\title{
Influência da Translucidez, Cor e Espessura da Cerâmica na Resistência de União de um Cimento Resinoso Fotoativado que Contem Ivocerin como Fotoiniciador.
}

\section{Mônica Scarazzati, Lincoln P. S. Borges, Lourenço Correr-Sobrinho, Américo B. Correr. Ana Rosa Costa.}

\section{Resumo}

Este estudo avaliou o efeito da translucidez ( $\mathrm{LT}$ - baixa translucidez, MT - média translucidez e HT - alta translucidez), cor (BL2, A1 e A3,5) e espessura $(0,5 ; 1,5$ e 2,0 mm) da cerâmica à base de dissilicato de lítio na resistência da união ao microcisalhamento $(\mathrm{RU} \mu \mathrm{C})$ do cimento resinoso Variolink Esthetic LC. Cento e trinta e cinco discos da cerâmica IPS e.max Press foram preparados e separados em 27 grupos $(n=5)$ de acordo com a translucidez, cor e espessura. $O$ Aparelho LED - Valo (Ultradent) foi utilizado como fonte de luz através da cerâmica. O teste de RU $\mu \mathrm{C}$ foi realizado à velocidade de $1,0 \mathrm{~mm} /$ minuto até ocorrer falha. Os dados foram submetidos à Análise de Variância 3 fatores e ao teste de Tukey $(\alpha=0,05)$. Os valores de resistência ao microcisalhamento foram estatisticamente influenciados pela translucidez, espessura e cor $(p=0,0000)$. A cor $A 1$ na espessura de $0,5 \mathrm{~mm}(46,3 \pm 5,0)$ apresentou valores de $R U \mu C$ estatisticamente superiores em relação a espessura de 2,0 mm $(33,6 \pm 3,7)$ embora não diferiu da espessura 1,5 mm $(46,7 \pm 7,2)$. Não houve diferença estatística para HT nas cores A3.5 e BL2 independentemente da espessura $(p>0,005)$. Em geral, nenhuma diferença significativa entre as cores foi observada, independente da espessura, para baixas translucidez (LT e MO). Para cor mais opaca (BL2), nenhuma diferença estatística entre as espessuras foi observada independente da translucidez.

\section{Palavras-chave:}

Cerâmica, Cimento Resinoso,Resistência de União.

\section{Introdução}

A Canforoquinona ainda é o fotoiniciador mais utilizado em compósitos resinosos, porém, sua baixa reatividade requer a presença de uma amina terciária para desencadear a reação. Esse sistema promove alterações da cor ao longo do tempo, comprometendo a estética. ${ }^{1}$ O VariolinEsthetic LC é o primeiro cimento resinoso livre de amina, o qual contém Ivocerin como fotoiniciador, que caracteriza-se por ser altamente reativo em pequenas quantidades, além disso, contem tiocarbamida, um componente que melhora a estabilidade de cor ao longo do tempo. ${ }^{1}$

Alguns fatores relacionados a cerâmica restauradora podem interferir no resultado final como a translucidez, espessura e cor influenciando negativamente na transmissão de luz, interferindo, portanto, na qualidade da polimerização do cimento resinoso.

\section{Resultados e Discussão}

Figura 1. Metodologia para o teste de resistência ao microcisalhamento.

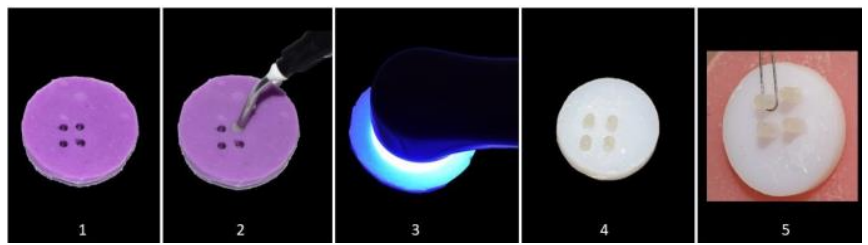

Os dasdos foram submetidos a análise de Variância 3 fatores e ao teste de Tukey $(\alpha=0,05)$.

Os valores de resistência ao microcisalhamento foram estatisticamente influenciados pela translucidez, espessura e cor $(p=0,0000)$.
Tabela 1. Média e desvio padrão da resistência ao microcisalhamento em função da Translucidez Cor e Espessura da cerâmica IPS e.max Press.

\begin{tabular}{|c|c|c|c|c|}
\hline Translucidez & Espessura & & Cor & \\
\hline \multirow{4}{*}{ HT } & & A1 & A3,5 & BL2 \\
\hline & $0,5 \mathrm{~mm}$ & $46,3(5,0) a A^{\#}$ & $37,3(6,1) a^{\#}$ & $44,7(7,8) a^{A B^{\#}}$ \\
\hline & $1,5 \mathrm{~mm}$ & $46,7(7,2) a A^{\#}$ & $31,4(6,1) \mathrm{aB}^{\#}$ & $41,3(4,1) a A^{\#}$ \\
\hline & $2,0 \mathrm{~mm}$ & $33,6(3,7) b A^{\# \$}$ & $33,4(5,0) a A^{\#}$ & $38,1(1,7) a A^{\#}$ \\
\hline \multirow{3}{*}{ LT } & $0,5 \mathrm{~mm}$ & $46,9(6,2) a A^{\#}$ & $40(3,4) a A^{\# \$}$ & $40,4(4,1) a A^{\#}$ \\
\hline & $1,5 \mathrm{~mm}$ & $37,1(3,2) a A^{\$}$ & $43,2(8,0) a A^{\$}$ & $38,5(7,9) a A^{\#}$ \\
\hline & $2,0 \mathrm{~mm}$ & $40,4(5,9) a b A^{\#}$ & $36,4(2,7) a A^{\#}$ & $38,4(3,3) a A^{\#}$ \\
\hline \multirow{3}{*}{ MO } & $0,5 \mathrm{~mm}$ & $45,6(1,3) \mathrm{aA}^{\#}$ & $45,8(1,4) a A^{\$}$ & $44,8(2,5) a A^{\#}$ \\
\hline & $1,5 \mathrm{~mm}$ & $39,0(4,9) a A^{\$}$ & $31,9(5,8) b A^{\#}$ & $38,5(8,8) a A^{\#}$ \\
\hline & $2,0 \mathrm{~mm}$ & $26,2(3,9) b B^{\$}$ & $20,2(5,9) \mathrm{cB}^{\$}$ & $42,4(3,8) a A^{\#}$ \\
\hline
\end{tabular}

Médias seguidas de letras distintas diferem entre si $(p \leq 0,05)$; letras maiúsculas na horizontal comparando espessura dentro de cada cor minúsculas na vertical comparando cor dentro de cada espessura. \#Difere em translucidez nas mesmas condições de espessura. \$Difere em cor nas mesmas condições de espessura.

\section{Conclusões}

Em geral, nenhuma diferença significativa entre as cores foi observada, independente da espessura, para baixas translucidez (LT e MO).

Para cor mais opaca (BL2), nenhuma diferença estatística entre as espessuras foi observada independente da translucidez.

\section{Agradecimentos}

Ao Programa Institucional de Bolsas de Iniciação Científica da UNICAMP (PIBIC-CNPq).

1 Santini A, Gallegos IT, Felix CM. Photoinitiators in dentistry: a review. Primary Dental Journal 2013;2:30-3 